\title{
The role of fibrinogen in acute ischaemic stroke
}

\author{
Marieta Peycheva, Tanya Deneva, Zahari Zahariev \\ Medical University in Plovdiv, Plovdiv, Bulgaria
}

\begin{abstract}
Aim. This study aimed to explore associations between fibrinogen and acute ischaemic stroke, neurological impairment, cerebral ischaemia, and clinical evaluation of stroke patients.

Materials and methods. The study involved 153 patients categorised into two groups: patients with acute ischaemic stroke, and patients with risk factors but who had not had a stroke. Blood samples were collected to analyse the serum level of fibrinogen. The time from stroke onset to blood test was noted. The National Institutes of Health Stroke Scale was used to determine the neurological disability of the stroke patients upon hospital admission and upon discharge. Cerebral CT was performed on the same group of patients during the first $24 \mathrm{~h}$ after stroke onset and evidence of early ischaemic lesions was recorded. The stroke cases were divided into subgroups according to the TOAST classification.

Results. Patients with ischaemic stroke had a significantly increased mean level of fibrinogen ( $>4 \mathrm{~g} / \mathrm{l})$. Analysis of stroke subtypes shows that patients with undetermined cause of stroke and patients with atherosclerotic stroke had a significantly higher median level of fibrinogen compared to patients with some other types of stroke. No significant connection was found between fibrinogen level and neurological deficit. A positive linear relationship was established between fibrinogen and blood sample time. A negative relation was established between the clinical evolution of ischaemic stroke patients and fibrinogen level. A significant relation between fibrinogen level and the presence of ischaemic lesions on cerebral CT was observed: patients with a fibrinogen level $>3.41 \mathrm{~g} / \mathrm{l}$ showed a 3.29-times increased risk of ischaemic lesions.
\end{abstract}

Conclusion. Fibrinogen is a reliable biomarker that could characterise acute ischaemic stroke.

Key words: biomarkers, ischaemic stroke, fibrinogen

(Neurol Neurochir Pol 2021; 55 (1): 74-80)

\section{Introduction}

Ischaemic stroke is a result of different modifiable and non-modifiable risk factors and several inflammatory mechanisms and biomarkers are involved in its pathogenesis $[1,2]$. Fibrinogen plays an important role in the coagulation cascade, in platelet aggregation, participates in the interactions between leukocytes and endothelial cells, and determines blood viscosity $[3,4,5]$. It also has non-haemostasis-related functions because it plays a role in cellular and matrix interactions, inflammatory response, wound healing, and cancer progression $[6,7]$. In population studies, serum fibrinogen levels serve as predictors of vascular thrombosis involving the coronary and peripheral arteries, but its role in cerebrovascular disease is yet to be fully established $[8,9]$.
Aim

The aim of this study was to investigate associations between fibrinogen and acute ischaemic stroke, neurological impairment, cerebral ischaemia and clinical evaluation of stroke patients. We also tried to identify the characteristics of stroke among the Bulgarian population.

\section{Materials and methods}

An observational, cross-sectional study was conducted for six months (1 November 2017 to 30 April 2018 inclusive). It enrolled consecutively 153 patients under medical observation in the Clinic of Neurology, UMHAT St.George, Plovdiv, Bulgaria. It was approved by the Local Ethical Committee. 
The inclusion criteria included risk factors for ischaemic stroke, such as a history of hypertension, carotid atherosclerosis, diabetes mellitus, atrial fibrillation and cardiovascular disease. The exclusion criteria were autoimmune diseases, cancer and inflammatory diseases. The selection was made by means of medical history, physical examination and laboratory investigations. Two groups were compiled: patients with acute ischaemic stroke who were not treated with rt-PA, and patients with risk factors but with no history of ischaemic stroke. Information about comorbidity in all patients was collected through medical history, physical examination, laboratory investigations, electrocardiogram monitoring and extracranial carotid duplex ultrasound investigation. Blood samples from all the patients were collected to analyse the level of fibrinogen. Measurement of serum fibrinogen was performed coagulometrically by an automated Sysmex Cs 2000 analyser. The fibrinogen unit of measurement is $\mathrm{g} / \mathrm{l}$, with a reference range of 2-4 g/l.

In the stroke subgroup, the time from stroke onset until taking the blood sample was recorded. The National Institutes of Health Stroke Scale (NIHSS) was used to determine the neurological disability of the stroke patients upon hospital admission and upon discharge. Clinical evolution in ischaemic stroke patients (i.e. with improvement, with no change, or with deterioration) was analysed based on the dynamics of the neurological deficit assessed by NIHSS. Cerebral computed tomography (CT) was performed on the same group of patients during the first $24 \mathrm{~h}$ after stroke onset, and evidence of early ischaemic lesions was recorded. The stroke cases were divided into subgroups according to the Trial of Org 10,172 in Acute Stroke Treatment (TOAST) classification.

The data was analysed using SPSS (IBM, Armonk, NY, USA) Version 25 [10] and Med-Calc Statistical Software (MedCalc, Ostend, Belgium) Version 18.11.3 [11]. The descriptive statistics for continuously measured variables included mean values $\pm S D$; and the frequencies and percentages for nominal and dichotomous variables. Continuously measured variables were screened for violations of normality using the
Kolmogorov-Smirnov test. To examine significant differences between two groups, we performed independent sample t-tests, when normality was observed (Kolmogorov-Smirnov $P>0.05)$ and we used the Mann Whitney $U$ Test when normality was not in place $($ Kolmogorov-Smirnov $\mathrm{P}<0.0$ ). Comparisons of more than two groups when normality was not observed were carried out using Kruskal-Wallis test and Dunn's test for post-hoc analysis. To identify the fibrinogen criterion with the corresponding sensitivity and specificity, we applied receiver operating characteristic (ROC) curve analysis and Youden's index. The optimal criterion was used to recode fibrinogen into positive and negative cases, and to calculate the odds ratio (OR) with the incidence of ischaemic lesions evident on cerebral CT. For the stroke patients, we examined the connection between fibrinogen and the neurological deficit measured by NIHSS, the time of fibrinogen testing, and stroke evolution through correlation analysis. Pearson correlation was employed when variables were measured continuously and normally distributed, and Spearman correlation in all other cases. The results were interpreted as statistically significant if the $\mathrm{P}$ values were $<0.05$.

\section{Results}

\section{Demographic and clinical characteristics of patients}

The study involved 153 patients with a mean age of 65.08 \pm 10.65 years, of whom 82 were male $(53.6 \%)$. Seventy-nine patients had suffered an ischaemic stroke, and 74 had not suffered an ischaemic stroke. The two groups did not differ significantly in mean age $(P=0.386)$, gender distribution $(P=0.235)$, cases with carotid plaques $(\mathrm{P}=0.439)$, cases with hypertension $(\mathrm{P}=0.182)$, or cases with diabetes $(\mathrm{P}=0.083)$. A significantly higher percentage of the patients with ischaemic stroke had non-valvular atrial fibrillation $(\mathrm{P}<0.001)$ and cardiovascular diseases $(P=0.035)$ (ischaemic heart disease, valvular heart disease, heart failure and other diseases). Demographic and clinical data is set out in Table 1 .

Table 1. Demographic and clinical characteristics of patients

\begin{tabular}{|c|c|c|c|c|c|}
\hline \multicolumn{2}{|l|}{ Variables } & $\begin{array}{c}\text { Total } \\
(\mathrm{N}=153)\end{array}$ & $\begin{array}{l}\text { Stroke patients } \\
\qquad(\mathbb{N}=79)\end{array}$ & $\begin{array}{l}\text { Non stroke patients } \\
\qquad(\mathbb{N}=74)\end{array}$ & $\mathbf{p}$ \\
\hline \multicolumn{2}{|c|}{ Age $(\bar{X} \pm S D)$ (range) } & $65.08 \pm 10.65(38-88)$ & $65.81 \pm 11.38(39-88)$ & $64.31 \pm 9.83(38-85)$ & $0.386^{\mathrm{a}}$ \\
\hline \multirow[t]{2}{*}{ Gender $(\mathrm{N}, \%)$} & Male & $82(53.6 \%)$ & $46(58 \%)$ & $36(48.6 \%)$ & \\
\hline & Female & $71(46.4 \%)$ & $33(42 \%)$ & $38(51.4 \%)$ & $0.235^{\mathrm{b}}$ \\
\hline \multicolumn{2}{|c|}{ Carotid plaques $(\mathrm{N}, \%)$} & $120(78.4 \%)$ & $64(81 \%)$ & $56(75.7 \%)$ & $0.439^{c}$ \\
\hline \multicolumn{2}{|c|}{ Hypertension (N, \%) } & $129(84.3 \%)$ & 70 (88.6\%) & $59(79.7 \%)$ & $0.182^{c}$ \\
\hline \multicolumn{2}{|c|}{ Atrial fibrillation $(\mathrm{N}, \%)$} & $26(17 \%)$ & $24(30.4 \%)$ & $2(2.7 \%)$ & $0.000^{* * c}$ \\
\hline \multicolumn{2}{|c|}{ Cardiovascular diseases $(\mathrm{N}, \%)$} & $70(45.8 \%)$ & $43(54.4 \%)$ & $27(36.5 \%)$ & $0.035^{* c}$ \\
\hline \multicolumn{2}{|l|}{ Diabetes (N, \%) } & $49(32 \%)$ & $20(25.3 \%)$ & $29(39.2 \%)$ & $0.083^{c}$ \\
\hline
\end{tabular}

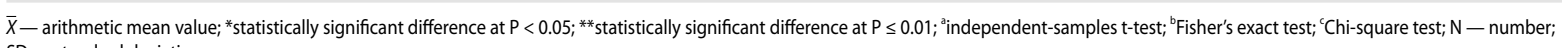
$\mathrm{SD}-$ standard deviation 
Table 2. Comparison of patients with and without ischaemic stroke on fibrinogen serum levels

\begin{tabular}{|c|c|c|c|}
\hline Fibrinogen g/l & $\begin{array}{l}\text { Stroke patients } \\
\qquad \mathbf{N}=\mathbf{7 9}\end{array}$ & $\begin{array}{l}\text { Non stroke patients } \\
\qquad N=74\end{array}$ & $\mathbf{p}$ \\
\hline $\bar{X} \pm \mathrm{SD}$ & $3.78 \pm 1.16$ & $3.30 \pm 0.79$ & \\
\hline Median (range) & $3.23(0.66-7.32)$ & $1.34(1.63-5.23)$ & $0.012^{* a}$ \\
\hline Number $(\%)>4 \mathrm{mg} / \mathrm{l}$ & $28(35 \%)$ & $12(16 \%)$ & $0.01^{* * \mathrm{~b}}$ \\
\hline
\end{tabular}

$\bar{X}$ - arithmetic mean value; SD - standard deviation; Range - Minimum-Maximum value; ${ }^{a}$ test for independent samples; ${ }^{b}$ Fisher's test; ${ }^{*}$ Statistically significant difference at $p<0.05 ;{ }^{*}$ Statistically significant difference at $p \leq 0.01$

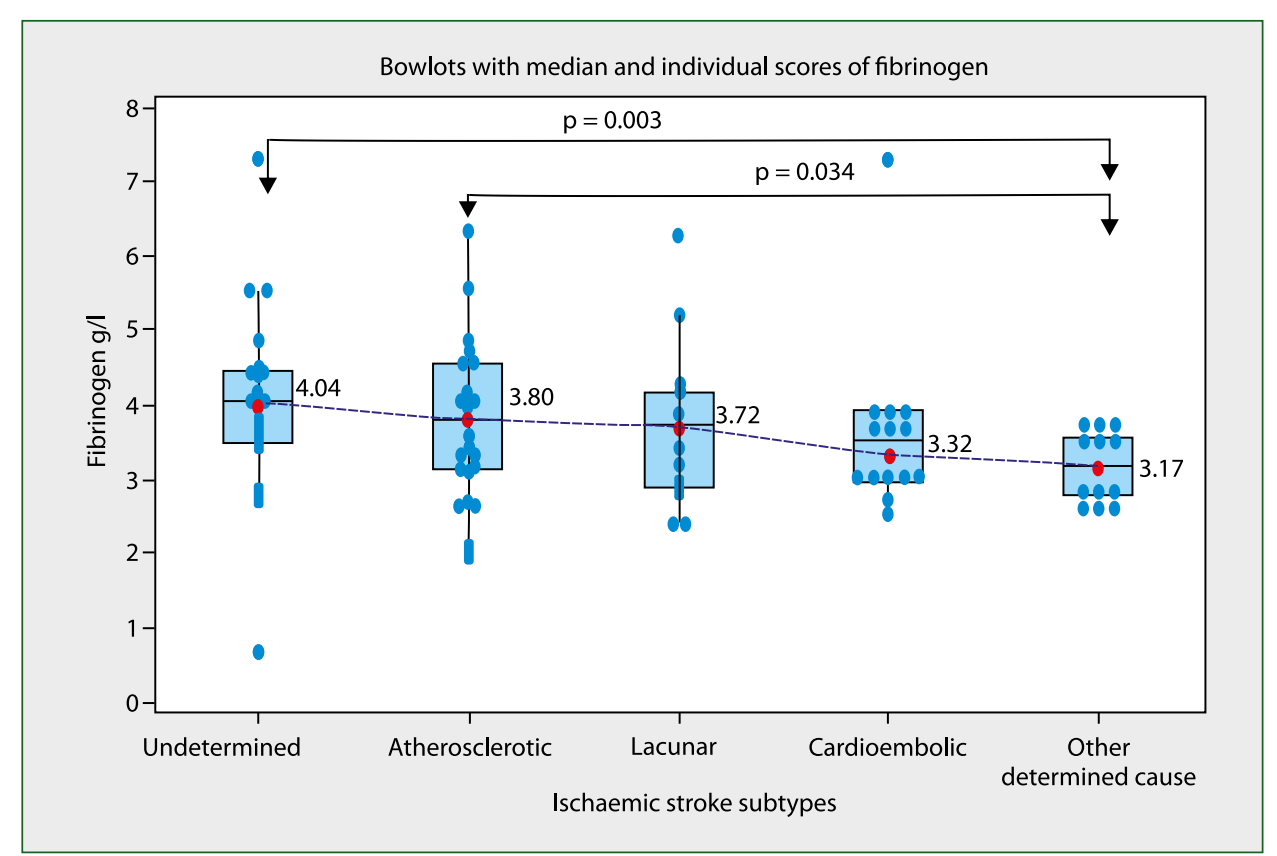

Figure 1. Boxplots of fibrinogen levels across ischaemic stroke subtypes

The fibrinogen level did not show a significant association with gender, $(\mathrm{p}=0.426)$ with similar mean levels in the male $(3.51 \pm 1.05 \mathrm{~g} / \mathrm{l})$ and female $(3.66 \pm 1.05 \mathrm{~g} / \mathrm{l})$ subgroups. A significant association was observed between fibrinogen levels and patient age $(\mathrm{p}<0.001)$ with mean values across age groups as follows: $<40$ years: $2.64 \pm 2.80$; $40-50$ years: $3.08 \pm 0.56$; 51-60 years: $3.74 \pm 1.02 ; 61-70$ years: $3.40 \pm 0.73$; $>70$ years: $3.81 \pm 1.22$. Specifically, the patients in age group $>70$ years had a significantly higher fibrinogen level than patients in age group $<40$ years $(\mathrm{p}<0.001)$ or than patients in age group $40-50(\mathrm{p}=0.023)$. Also, the patients in the youngest age group ( $<40$ years) showed a significantly lower fibrinogen level than those in age groups 51-60 years $(\mathrm{p}>0.001), 61-70(\mathrm{p}=0.006)$ and $>70(\mathrm{p}>0.001)$.

\section{Comparing patients with and without ischaemic} stroke according to fibrinogen level

In patients with ischaemic stroke, we found a significantly higher mean fibrinogen level $(3.78 \mathrm{~g} / \mathrm{l}$; median $3.23 \mathrm{~g} / \mathrm{l})$ than in patients without ischaemic stroke $(3.30 \mathrm{~g} / \mathrm{l}$; median $1.34 \mathrm{~g} / \mathrm{l})$, $\mathrm{p}=0.012$. The percentage of patients with increased fibrinogen level $(>4 \mathrm{~g} / \mathrm{l})$ was significantly higher in the ischaemic stroke group (35\%) than in the non-stroke group (16\%), p $=0.01$. The results are set out in Table 2.

In our study, according to the TOAST classification, the distribution of patients was as follows: $36 \%$ atherosclerotic stroke, 26.5\% undetermined cause, 19\% lacunar stroke, 11\% cardioembolic stroke, and 7.5\% some other determined cause.

Fibrinogen levels across ischaemic stroke subtypes were not normally distributed and are illustrated through boxplots with median and individual values in Figure 1. Kruskal-Wallis test showed a significant association between ischaemic stroke subtypes and fibrinogen levels, $\mathrm{p}=0.049$. The post-hoc analysis through Dunn's test revealed two significant differences, as follows: 1) Patients with undetermined cause of stroke had a significantly higher median level of fibrinogen $(4.04 \mathrm{~g} / \mathrm{l})$ compared to patients with stroke by another determined cause $(3.17 \mathrm{~g} / \mathrm{l}), \mathrm{p}=0.009 ; 2)$ A significantly higher median level of fibrinogen was also observed in patients with atherosclerotic stroke $(3.80 \mathrm{~g} / \mathrm{l})$ versus those with stroke by another determined cause, $p=0.039$. None of the other post-hoc comparisons showed statistically significant differences. 


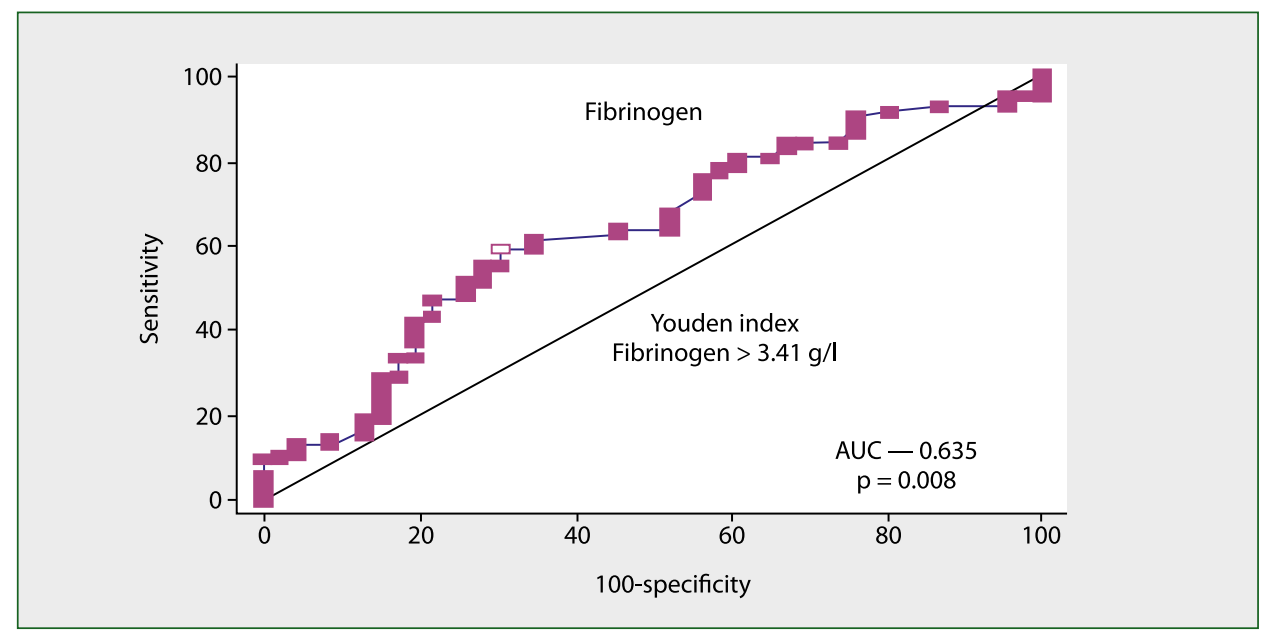

Figure 2. ROC curve between fibrinogen and presence of ischaemic lesions

Analysis of relation between fibrinogen and early ischaemic lesions from cerebral CT scan taken within first 24 hours

The potential relation between fibrinogen and ischaemic lesions was verified by analysis with ROC curve. A weak but statistically significant relationship was found, $\mathrm{AUC}=0.635$, $\mathrm{p}=0.008$.

Figure 2 illustrates the ROC curve between fibrinogen and the presence of ischaemic lesions. According to the Youden Index, fibrinogen values $>3.41 \mathrm{~g} / \mathrm{l}(95 \% \mathrm{CI}>2.85 \mathrm{~g} / \mathrm{l}$ to $>$ $4.06 \mathrm{~g} / \mathrm{l})$ were associated with patients with ischaemic lesions, with a sensitivity of $59 \%$ and specificity of $69.6 \%$.

According to the established Youden index criterion value (fibrinogen $>3.41 \mathrm{~g} / \mathrm{l}$ ), patients were categorised as fibrinogen positive $(>3.41 \mathrm{~g} / \mathrm{l})$ or negative $(\leq 3.41 \mathrm{~g} / \mathrm{l})$. The transcoded data was used to calculate the odds ratio (OR) of ischaemic lesions imaged by CT in fibrinogen-positive patients. A 3.29-times higher risk of ischaemic lesions was found in patients with a fibrinogen level $>3.41 \mathrm{~g} / \mathrm{l}(\mathrm{OR}=3.29$; $95 \%$ CI 1.53-7.08; $\mathrm{p}=0.0023$ ). The odds ratio and $95 \% \mathrm{CI}$ are illustrated in Figure 3.

Analysis of relation between fibrinogen, neurological deficit, test time, and clinical evolution in patients with ischaemic stroke

Results of the relation between fibrinogen and neurological deficit according to NIHSS scale, blood sample time and clinical evolution in ischaemic stroke patients (i.e. with improvement, with no change, or with deterioration) are set out in Table 3.

The results of correlation analysis showed no linear relation between fibrinogen and neurological deficit $(r=0.165$, $\mathrm{p}=0.153)$, a significant positive relation between fibrinogen and test time $(r=0.275, p=0.015)$, and a significant negative relation between fibrinogen and clinical evolution of stroke $\left(r^{s}=-0.341, p=0.012\right)$.

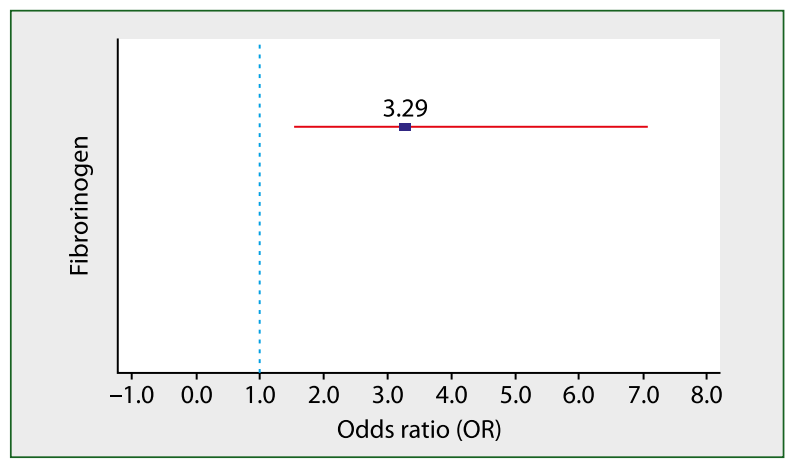

Figure 3. Increased risk of ischaemic lesions represented by CT at fibrinogen values $>3.41 \mathrm{~g} / \mathrm{l}$

Table 3. Results of correlation analysis for relationship between fibrinogen, neurological deficits, test time and clinical development in patients with ischaemic stroke

\begin{tabular}{lccc|}
\hline Variables & $\begin{array}{c}\text { Patient } \\
\text { numbers }\end{array}$ & $\begin{array}{c}\text { Correlation } \\
\text { coefficient }\end{array}$ & Significance \\
\hline $\begin{array}{l}\text { Neurological } \\
\text { deficit (NIHSS) }\end{array}$ & 79 & 0.165 & 0.153 \\
$\begin{array}{l}\text { Blood sample } \\
\text { time }\end{array}$ & 79 & 0.275 & $0.015^{* a}$ \\
$\begin{array}{l}\text { Clinical evolution } \\
\text { of stroke }\end{array}$ & 79 & -0.341 & $0.012^{* b}$ \\
$\begin{array}{l}{ }^{\circ} \text { Pearson correlation; }{ }^{*} \text { Spearman correlation; *Statistically significant correlation at } p<0.05 ; \\
{ }^{*} \text { Statistically significant correlation at } \mathrm{p} \leq 0.01\end{array}$
\end{tabular}

The significant correlation between fibrinogen and test time is illustrated in Figure 4, in which test time is presented in the following time periods: $24 \mathrm{~h} ;>24 \mathrm{~h}-72 \mathrm{~h} ;>72 \mathrm{~h}-120 \mathrm{~h}$; and $>120 \mathrm{~h}-240 \mathrm{~h}$. The chart shows that the highest level of fibrinogen was observed at $>120 \mathrm{~h}-240 \mathrm{~h}$. During this period, the fibrinogen level was higher $(4.71 \mathrm{~g} / \mathrm{l})$ than the upper limit for normal levels $(2-4 \mathrm{~g} / \mathrm{l})$. For the other periods, the mean values were similar and were within normal limits. 


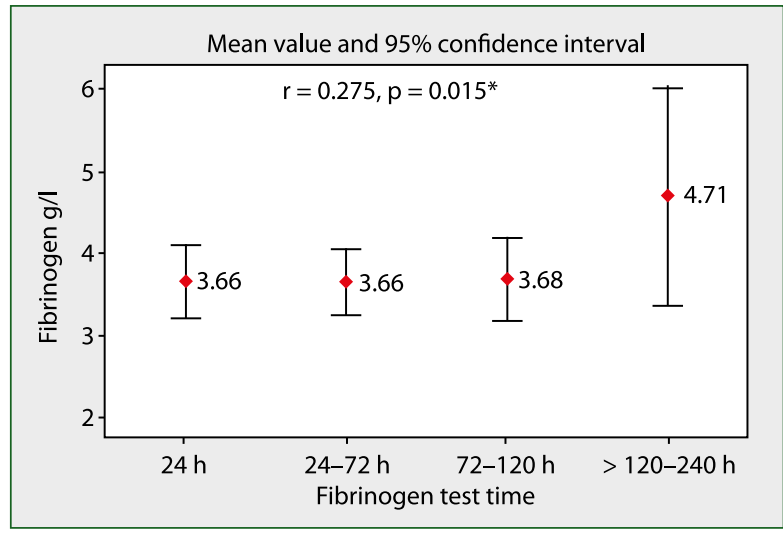

Figure 4. Mean fibrinogen level against blood sample test time

The relation between fibrinogen and the clinical evolution of stroke is illustrated in Figure 5. The correlation was negative: as patients with ischaemic stroke improved, fibrinogen levels decreased. The highest level of fibrinogen was observed in patients who experienced deterioration $(4.67 \mathrm{~g} / \mathrm{l})$. Next came those patients with no change, in whom the mean fibrinogen level was $4.40 \mathrm{~g} / \mathrm{l}$. It should be noted that in both groups the fibrinogen level was higher than the upper limit $(4 \mathrm{~g} / \mathrm{l})$. The lowest level of fibrinogen was observed in patients with an improved condition $(3.53 \mathrm{~g} / \mathrm{l})$, where the mean level was within the normal range.

\section{Discussion}

Our study involved 79 patients with acute ischaemic stroke who were admitted at the Clinic of Neurology, UMHAT St.George, Plovdiv, Bulgaria over a period of six months. The most common causes of stroke were large artery atherosclerosis (36\%), undetermined cause (26.5\%), and lacunar stroke (19\%). These results differ from the Stroke Data Bank of the German Stroke Foundation, which includes data from 5,017 patients with ischaemic stroke. They established the following aetiological subdivision of ischaemic strokes according to the TOAST classification: cardioembolism $25.6 \%$, undetermined cause $22.7 \%$, large artery atherosclerosis $20.9 \%$, lacunar stroke $20.5 \%$, stroke with concurrent mechanisms $6.9 \%$, and other determined aetiology 3.5\% [12]. Another large epidemiological study $(\mathrm{n}=81,193)$ that analysed the characteristics of hospitalisations for acute stroke in the province of Silesia, Poland, showed that large artery atherosclerosis (36.1\%) and cardioembolism (18.7\%) were the main causes of ischaemic stroke [13]. Our results come from a small number of patients, but could add some data to the literature describing the characteristics of Bulgarian stroke patients.

Fibrinogen is involved in the regulation of primary homeostasis, platelet aggregation and is a major factor determining blood and plasma viscosity $[3,14]$. Increased serum

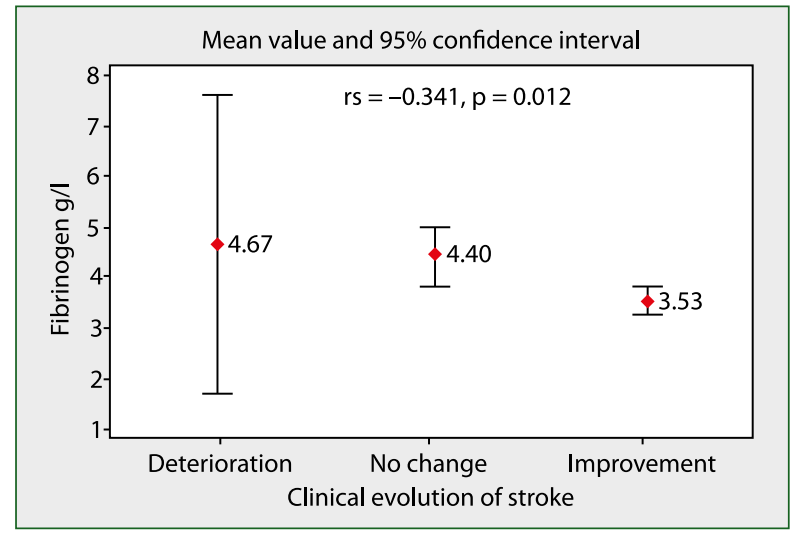

Figure 5. Mean fibrinogen levels relative to clinical evolution in stroke patients

fibrinogen levels have been associated with atherosclerosis involving the coronary, carotid, and peripheral arteries [14, $15,16]$. The role of fibrinogen as an acute-phase protein in inflammatory processes in cerebrovascular disease has been studied in several large cohort epidemiological studies. The West of Scotland Coronary Prevention Study, the United Kingdom TIA Aspirin Trial, the Dutch TIA Trial and the Oxford TIA Study indicate that serum fibrinogen levels serve as predictors of vascular disease involving the coronary and peripheral arteries, but in the case of cerebrovascular disease, despite the positive results, the data is uncertain and insufficiently reliable $[8,9,14]$. The Dutch TIA trial studied the relationship between fibrinogen and TIA and found a tendency to an increased risk of stroke at fibrinogen levels $>3 \mathrm{~g} / \mathrm{l}$, but this data does not have sufficient potency [17]. The Copenhagen City Heart Study [18], which included 8,755 patients and was conducted in three stages, concluded that fibrinogen is a marker of advanced atherosclerosis as well as a predictor of ischaemic stroke, especially in young and middle-aged men.

Our analysis of the role of fibrinogen in ischaemic stroke showed that stroke patients with a mean serum fibrinogen level $>4 \mathrm{~g} / \mathrm{l}$ had a significantly higher proportion (35\%) compared to the control group of patients with risk factors but who had not experienced a cerebrovascular accident (16\%). The fibrinogen level did not show a significant association with the patients' sex, but a significant association was observed between fibrinogen levels and patients' age. Specifically, the patients in age group $>70$ years had a significantly higher fibrinogen level than age group $<40$ years $(p<0.001)$ and age group $40-50(\mathrm{p}=0.023)$. Differences in fibrinogen level in an older subpopulation ( $>85$ years old) were also reported by Pastuszak et al. [19].

Results of fibrinogen levels in different subtypes of ischaemic stroke (TOAST classification) revealed that patients with undetermined cause of stroke had a significantly higher median level of fibrinogen $(4.04 \mathrm{~g} / \mathrm{l})$ compared to patients with stroke by another determined cause $(3.17 \mathrm{~g} / \mathrm{l}), \mathrm{p}=0.003$, and 
that there was a significantly higher median level of fibrinogen in patients with atherosclerotic stroke $(3.80 \mathrm{~g} / \mathrm{l})$ versus those with stroke by another determined cause, $\mathrm{p}=0.034$. Studies in the literature indicated negative results of the prognostic role of fibrinogen in differentiating aetiological subtypes of ischaemic stroke [20,21]. Despite the lack of a significant association between stroke types and elevated fibrinogen levels $(>4 \mathrm{~g} / \mathrm{l})$, some authors have noted that fibrinogen shows activity in vascular diseases close to that of $\mathrm{C}$-reactive protein and other proinflammatory factors $[14,22]$.

In order to establish the role of fibrinogen as a prognostic factor after an acute cerebrovascular accident, some additional analyses were performed regarding its relationship to neurological deficits, time dynamics of serum values, and short-term clinical development.

Regarding fibrinogen values and neurological deficits found in stroke patients in the first 24 hours after admission, no significant relationship was found. There was a positive linear relationship between serum fibrinogen concentrations and the blood test time, with the highest level observed in the period $>120-240$ hours. An inverse (negative) relationship was found with respect to the evolution of ischaemic stroke patients and serum fibrinogen levels. Patients with worsening of the condition showed the highest levels above the upper limit $(>4 \mathrm{~g} / \mathrm{l})$, while patients with improved condition showed the lowest average fibrinogen value within the normal reference range $(2-4 \mathrm{~g} / \mathrm{l})$. We also found a weak, but significant, relationship between fibrinogen levels and the presence of ischaemic lesions identified in the first 24 hours by cerebral CT. Patients with a level of fibrinogen $>3.41 \mathrm{~g} / \mathrm{l}$ showed a 3.29 -fold increased risk of ischaemic lesions (sensitivity $59 \%$ and specificity $69.6 \%$ ).

Our results contradict those obtained by Pikjia et al. [23], according to whom higher fibrinogen levels are associated with a lower risk of hospital death and worsening neurological deficit, defined as NIHSS $>15$. However, this study has several limitations, as it assesses only cases of stroke with established computed tomography hyperintense of the midbrain artery (a sign of vascular thrombosis). However, the authors found some significant relationships between fibrinogen concentrations and the size of blood clots and the volume of cerebral infarctions.

Two small studies (40 and 50 stroke patients) compared fibrinogen concentrations in the acute phase and the volume of cerebral infarction objectified by cerebral CT in the first 24 hours after onset [24,25]. Both reported a positive dependence, but declared the need to increase the number of surveyed contingents.

The study by Swarowska et al., involving 266 patients with primary acute ischaemic stroke, assessed the dynamics of serum fibrinogen levels on days 1, 7 and 14 after the incident and their relationship to neurological deficit and post-stroke outcome. The results show that persistently elevated fibrinogen levels are associated with more severe deficits and a worse prognosis [26].
Di Napoli et al. [20] assessed the one-year prognostic risk relative to serum fibrinogen levels measured in the first 24 hours in patients with acute stroke by comparing its association with C-reactive protein. The authors defined the probability of death or new vascular event as $21.1 \%, 27.9 \%$, and 51.7\%, respectively, in stroke patients broken down by fibrinogen values $<3.78 \mathrm{~g} / \mathrm{l}, 3.78-6.17 \mathrm{~g} / \mathrm{l}$, and $>6.17 \mathrm{~g} / \mathrm{l}$.

As fibrinogen is involved in the coagulation cascade, it is also important for the specific treatment of rt-PA in stroke patients. Low fibrinogen levels found before or immediately after fibrinolytic treatment are associated with a higher risk of cerebral haemorrhage [6]. This phenomenon is known as 'early fibrinogen degradation coagulopathy' and is due to the biological effects resulting from the rapid depletion of fibrinogen in the blood and the increase in degradation products (FDPs) [6]. According Shi et al., the increase in fibrinogen after intravenous thrombolysis is associated with an increased risk of death or major disability in patients with acute ischaemic stroke [27]. Our study included only stroke patients who were not treated with rt-PA, but the results from future studies on its dynamics during treatment may help neurologists to improve stroke outcomes in clinical settings.

\section{Conclusion}

Our results confirm the positive correlation of fibrinogen serum levels in patients with ischaemic stroke in the acute phase, as well as its role as a short-term prognostic factor in clinical development. This study also presents some of the characteristics of ischaemic stroke among the Bulgarian population.

Acknowledgements: This article is part of the research project 'Markers of inflammation associated with the nature and instability of plaques in carotid atherosclerosis' funded by Medical University Plovdiv, Bulgaria (project code 04/2015).

\section{References}

1. Boehme AK, Esenwa C, Elkind MSV. Stroke Risk Factors, Genetics, and Prevention. Circ Res. 2017; 120(3): 472-495, doi: 10.1161/CIRCRESAHA.116.308398, indexed in Pubmed: 28154098.

2. Anrather J, ladecola C. Infl am mation and stroke: an overview. Neurotherapeutics. 2016; 13(4): 661.

3. Drouet L. Fibrinogen: a treatable risk factor? Cerebrovasc Dis. 1996; 6: 2-6.

4. Harley S, Powell J. Fibrinogen upregulates the expression of monocyte chemoattractant protein-1 in human saphenous vein endothelial cells. Biochem J. 1999; 341: 739-744.

5. Hashimoto $\mathrm{H}$, Kitagawa $\mathrm{K}$, Hougaku $\mathrm{H}$, et al. C-reactive protein is an independent predictor of the rate of increase in early carotid atherosclerosis. Circulation. 2001; 104(1): 63-67, doi: 10.1161/ hc2601.091705, indexed in Pubmed: 11435339.

6. Bagoly Z, Szegedi I, Kálmándi R, et al. Markers of Coagulation and Fibrinolysis Predicting the Outcome of Acute Ischemic Stroke Thromboly- 
sis Treatment: A Review of the Literature. Front Neurol. 2019; 10: 513, doi: 10.3389/fneur.2019.00513, indexed in Pubmed: 31316444.

7. Weisel J. Fibrinogen and Fibrin. Advances in Protein Chemistry. 2005: 247-299, doi: 10.1016/s0065-3233(05)70008-5.

8. Pickering J, Elwood P, Bayer A, et al. Fibrinogen, Viscosity and White Blood Cell Count Predict Myocardial, but not Cerebral Infarction: Evidence from the Caerphilly and Speedwell Cohort. Thrombosis and Haemostasis. 2017; 87(03): 421-425, doi: 10.1055/s-0037-1613020.

9. Rumley A, Norrie J, Ford I, et al. Blood Rheology, Cardiovascular Risk Factors, and Cardiovascular Disease: The West of Scotland Coronary Prevention Study. Thrombosis and Haemostasis. 2017; 84(10): 553-558, doi: 10.1055/s-0037-1614066.

10. IBM SPSS Statistics for Windows, Version 25.0. Available from: https:// www.ibm.com/en/ analytics/ sps s-statistics-software.

11. MedCalc Statistical Software version 18.11.3. Available from:. https:// www.medcalc.org.

12. Grau AJ, Weimar C, Buggle F, et al. Risk factors, outcome, and treatment in subtypes of ischemic stroke: the German stroke data bank. Stroke. 2001; 32(11): 2559-2566, doi: 10.1161/hs1101.098524, indexed in Pubmed: 11692017.

13. Starostka-Tatar A, Łabuz-Roszak B, Skrzypek M, et al. Characteristics of hospitalizations due to acute stroke in the Silesian Province, Poland, between 2009 and 2015. Neurol Neurochir Pol. 2018; 52(2): 252-262, doi: 10.1016/j.pjnns.2017.11.010, indexed in Pubmed: 29221869.

14. Rothwell PM, Howard SC, Power DA, et al. Fibrinogen concentration and risk of ischemic stroke and acute coronary events in 5113 patients with transient ischemic attack and minor ischemic stroke. Stroke. 2004; 35(10): 2300-2305, doi: 10.1161/01. STR.0000141701.36371.d1, indexed in Pubmed: 15345800.

15. Enos WF, Holmes RH, Beyer J, et al. Coronary disease among United States soldiers killed in action in Korea; preliminary report. J Am Med Assoc. 1953; 152(12): 1090-1093, doi: 10.1001/ jama.1953.03690120006002, indexed in Pubmed: 13052433.

16. Maresca G, Di Blasio A, Marchioli R, et al. Measuring plasma fibrinogen to predict stroke and myocardial infarction: an update. Arterioscler Thromb Vasc Biol. 1999; 19(6): 1368-1377, doi: 10.1161/01. atv.19.6.1368, indexed in Pubmed: 10364066.

17. The Du. Trial Study Group. Predictors of major vascular events inpatients with a transient ischemic attack or nondisabling stroke. Stroke. 1993; 24: 527-531.
18. Kofoed S, Wittrup H, Sillesen $\mathrm{H}$, et al. Fibrinogen predicts ischaemic stroke and advanced atherosclerosis but not echolucent, rupture-prone carotid plaques: the Copenhagen City Heart Study. Eur Heart J. 2003; 24(6): $567-76$

19. Pastuszak Ż, Czernicki Z, Koszewski W, et al. Malignant middle cerebral artery (MCA) infarction in people over 85 years old - Diagnosis, management and risk factors. Neurol Neurochir Pol. 2018; 52(3): 311-317, doi: 10.1016/j.pjnns.2017.12.005, indexed in Pubmed: 29705052

20. Di Napoli M, Papa F, Bocola V. Prognostic influence of increased C-reactive protein and fibrinogen levels in ischemic stroke. Stroke. 2001; 32(1): 133-138, doi: 10.1161/01.str.32.1.133, indexed in Pubmed: 11136928.

21. Liu LB, Li Mu, Zhuo WY, et al. The role of hs-CRP, D-dimer and fibrinogen in differentiating etiological subtypes of ischemic stroke. PLoS One. 2015; 10(2): e0118301, doi: 10.1371/journal.pone.0118301, indexed in Pubmed: 25680111.

22. Kaptoge S, Di Angelantonio E, Lowe G, et al. Emerging Risk Factors Collaboration. Association of fibrinogen, C-reactive protein, albumin, or leukocyte count with coronary heart disease: meta-analyses of prospective studies. JAMA. 1998; 279(18): 1477-1482, doi: 10.1001/ jama.279.18.1477, indexed in Pubmed: 9600484.

23. Pikija S, Trkulja V, Mutzenbach JS, et al. Fibrinogen consumption is related to intracranial clot burden in acute ischemic stroke: a retrospective hyperdense artery study. J TransI Med. 2016; 14(1): 250, doi: 10.1186/s12967-016-1006-6, indexed in Pubmed: 27576312.

24. Khandait $\mathrm{V}$, et al. Study of fibrinogen levels in patients of acute stroke. Int J Res Med Sci. 2019; 7(1): 20-24.

25. Azam R, Khan M, Arshed A. Correlation between Mean Plasma Fibrinogen Level and Mean Lesion Volume on CT scan in Acute Ischemic Stroke. PJMHS Oct-Dec. 2015; 9(4).

26. Swarowska M, Janowska A, Polczak A, et al. The sustained increase of plasma fibrinogen during ischemic stroke predicts worse outcome independently of baseline fibrinogen level. Inflammation. 2014; 37(4): 1142-1147, doi: 10.1007/s10753-014-9838-9, indexed in Pubmed: 24531853

27. Shi J, Shi R, Qin W, et al. Dynamic Changes in Fibrinogen and Prognosis of Acute Ischemic Stroke Patients Treated with Intravenous Thrombolysis. Neurotox Res. 2020; 38(3): 775-784, doi: 10.1007/ s12640-020-00241-w, indexed in Pubmed: 32572815. 